REVIEW

\title{
Hard work never hurt anyone: or did it? A review of occupational associations with soft tissue musculoskeletal disorders of the neck and upper limb
}

\section{K Walker-Bone, C Cooper}

Ann Rheum Dis 2005;64:1391-1396. doi: 10.1136/ard.2003.020016

Pain in the neck and upper limb is common and contributes considerably to absence from work due to sickness. Evidence suggest that prolonged abnormal posture and repetition contribute to such conditions. Psychosocial risk factors may also play a part in the aetiology of upper limb disorders.

See end of article for authors' affiliations

.....................

Correspondence to: Dr K Walker-Bone, Brighton and Sussex Medical School, Mayfield House, University of Brighton, Falmer, Brighton, East Sussex BN1 9PH, UK; k.walker-bone@ bsms.ac.uk

Accepted 18 April 2005
A mong the lay population and popular press, there is a widely held belief that certain types of work cause upper limb disorders (ULDs). Indeed, such an association was first proposed by Ramazzini in the early eighteenth century, who recorded that pain in the upper limb is related to "...constant sitting, the perpetual motion of the hand in the same manner, and the attention and application of the mind". ' However, despite a substantial body of epidemiological and scientific publications, this is a field beset by controversy. A lack of consensus based case definitions, lack of "gold standards" for the clinical diagnosis of most of these conditions, problems associated with the measurement of exposure, failure to control for known confounding factors, and an adversarial and acrimonious medicolegal climate that has grown up owing, in large part, to claims for compensation, have all contributed to the uncertainty. This review aims at summarising the state of knowledge of this topic, highlighting the strengths and weaknesses of published reports, and identifying those issues that remain controversial and require further study.

\section{METHODS}

Epidemiological surveys of neck or upper limb complaints were located through Embase (Excerpta Medica) and Medline (National Library of Medicine, USA) databases 19802001, searching for all upper extremity regions, including the neck, and terms for specific diagnoses of disorders considered to be musculoskeletal ULDs; the search was refined with the terms: diagnosis, classification, occupation, risk factors, mechanical, work related, or occupational. There are a vast number of publications (>2200 studies), and therefore emphasis was placed on retrieved articles that furnished new information on the association between occupation and occupational exposures and the musculoskeletal disorders of interest, or authoritative systematic analyses of previous studies.
Methodological issues

Classification of soft tissue disorders of the neck and upper limb

Epidemiological research relies upon the use of diagnostic criteria capable of separating states of disease with different causes, prognosis, or response to treatment. Soft tissue musculoskeletal disorders of the neck and upper limb comprise a heterogeneous group of conditions. At one end of the spectrum are relatively clear cut specific upper limb conditions-for example, de Quervain's tenosynovitis, lateral epicondylitis, rotator cuff tendonitis, and carpal tunnel syndrome, but at the other end of the spectrum are non-specific regional pain syndromes-for example, forearm pain, with few objective physical findings and little in the way of demonstrable pathology. ${ }^{2}$ In the latter group, labels such as "repetitive strain injury", "cumulative trauma disorder", and "work related upper limb pain" have often been used, but such terms are tautological and unhelpful. ${ }^{3}$

Until recently, epidemiological research in this field had been hampered by the absence of an agreed system of classification for these conditions. ${ }^{4}$ Important developments were, however, made recently with the publication of two sets of consensus criteria for the diagnosis of ULDs in the $\mathrm{UK}^{5}$ and Europe. ${ }^{6}$ Even more recently, Helliwell and colleagues used a multivariate modelling technique to identify the core variables that classified cases of soft tissue ULDs $^{7}$ (table 1). Moreover, the Harrington criteria have been used as a basis for the development of a standardised system of examination for ULDs, and the resultant Southampton examination protocol has been shown to perform reliably ${ }^{8}$ and have face validity for the diagnosis of these conditions. ${ }^{9}$

\section{Study design}

Soft tissue rheumatic disorders tend to be episodic and recurrent, making measurement of incidence methodologically challenging. Until recently, therefore, most surveys have been cross sectional and focused on prevalence. Such surveys provide useful evidence on the burden of disease and potential associations with risk factors, but are less informative in establishing cause and effect. Cross sectional surveys cannot readily distinguish risk factors that prolong (as

Abbreviations: $\mathrm{Cl}$, confidence interval; CTS, carpal tunnel syndrome; OR, odds ratio; RSI, repetitive strain injury; ULDs, upper limb disorders 


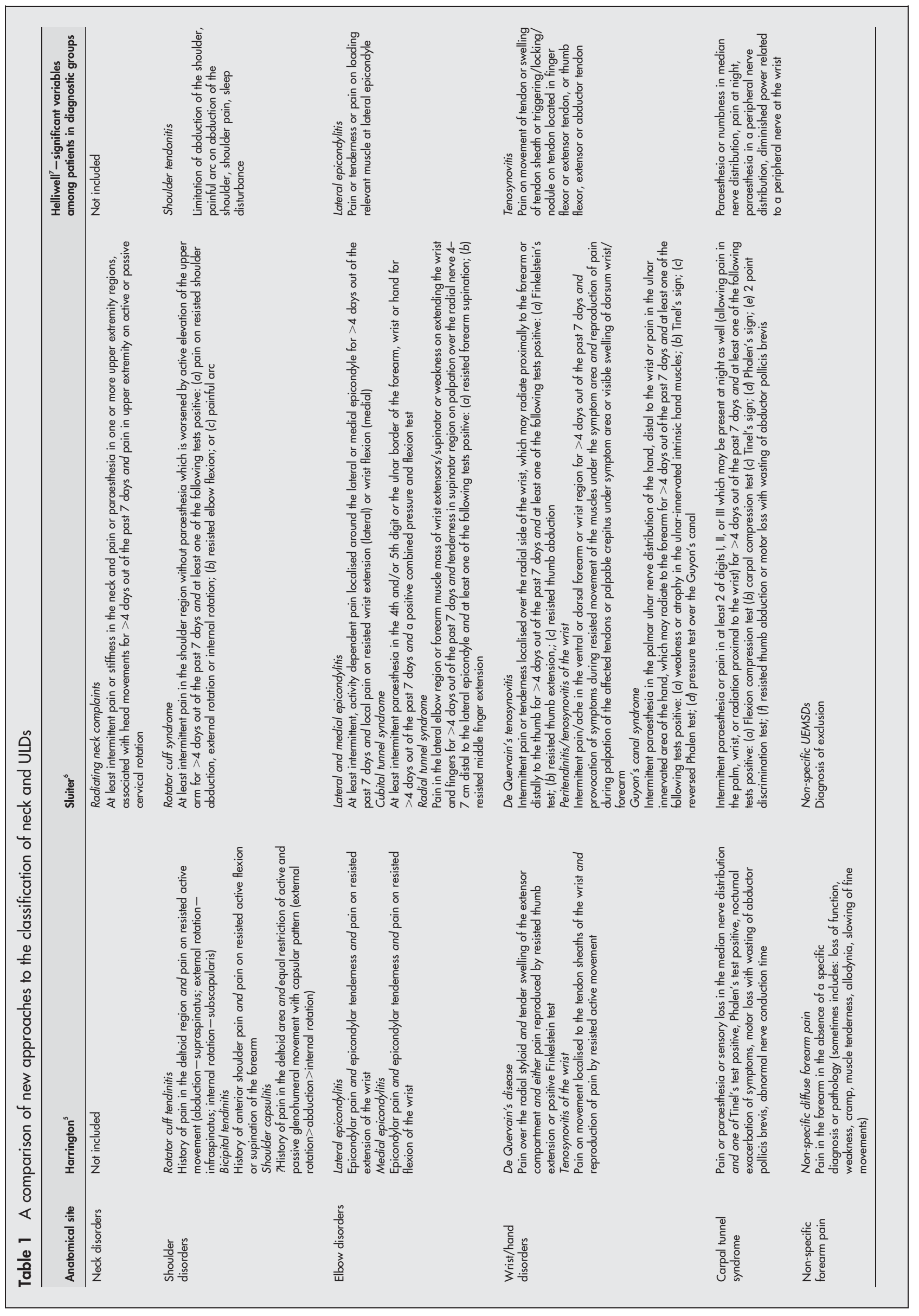


opposed to cause) a musculoskeletal disorder, and cross sectional occupational studies are prone to selection bias and the "healthy worker effect" (in which those worst affected tend to get selected out of employment, leading to an underestimate of the true risk). As we will see below, our knowledge in this field has recently been considerably enhanced by the publication of prospective studies of the incidence of neck and ULDs, in community and occupational settings.

\section{Assessment of exposures}

The exposures that are suspected of causing or aggravating soft tissue ULDs are complex and difficult to measure. ${ }^{10}$ Mechanical exposures combine elements of force, frequency, repetition, and movement. Techniques for direct observation and analysis of complex physical activities exist, but are generally time consuming, expensive, and suitable only for small scale application, while surrogates of exposure such as job title may be insufficiently sensitive, with considerable variation in work activities between people in ostensibly similar jobs. Psychosocial risk factors in the work environment (too few or too many job demands, too little support from colleagues, job security, ambiguity of responsibilities) are also considered important, but no standard rubric exists for the measurement of these factors and, in consequence, assessment methods vary from study to study. ${ }^{11}$

\section{Classification of outcomes and exposures}

Given the above, random (unbiased) misclassifications of outcomes and exposures are relatively common and the effect is generally to reduce estimates of risk to the no-effect level, thus impairing the ability of a study to detect associations which truly exist. However, non-random (biased) associations may arise if subjects with symptoms have an exaggerated recall of exposures, or if those with exposures that worry them pay more attention to their symptoms. The potential for this arises most readily in cross sectional studies, in which the assessment of exposure is self reported and subjective, and where the outcome is uncorroborated by independent physical examination (many of the available studies fit this description).

\section{Association of occupation with neck disorders}

Neck pain is common among adults in developed countries and contributes importantly to the demand for medical services and the economic burden of absence from work due to sickness. Population based studies suggest a lifetime prevalence of over $70 \%$ and a point prevalence of between $12 \%$ and $34 \% .{ }^{12}$ Given this high background prevalence, it is unsurprising that there have been more than 40 published epidemiological studies examining the associations between neck pain and occupation. ${ }^{10}$ The studies are heterogeneous, varying in design, population (for example, automobile assembly workers, factory workers, secretaries, poultry workers, scissor makers, sewing machine operators, healthcare employees, grocery checkers), exposure assessment, outcome measurement (neck pain, neck/shoulder pain, physical examination), analysis, and presentation. When subjected to rigorous methodological criteria, few studies are found to be acceptable. ${ }^{13}$ Several groups have undertaken systematic reviews of these publications ${ }^{2} 0^{14}$ and, despite some heterogeneity of their conclusions due to the application of different quality assessment criteria, the results suggest that neck pain is associated with exposure to sustained abnormal posture (for example, prolonged sitting, neck/trunk held in prolonged flexion or rotation), forceful and/or repetitive tasks, poor workplace support from supervisors/colleagues, high demands on the worker, and poor control over working patterns.
Many of the early epidemiological publications focused only on mechanical workplace factors, thereby omitting another potentially modifiable aspect of workplace design. Circumstantial evidence is beginning to suggest that the effects of mechanical workplace exposures-for example, abnormal posture, might be modified by psychosocial workplace factors such as decision latitude, psychological workload, and relationships within the workplace. One recent such study is that of Croft and colleagues, in which poor self assessed health status and poor psychological health predicted subsequent neck pain after 1 year, regardless of the employment status of the person. ${ }^{15}$ According to the results of another longitudinal study, depressive symptoms predicted the subsequent incidence of neck pain. ${ }^{16}$ The interaction between mechanical and psychosocial risk factors may therefore be complex, and well designed longitudinal studies, with validated criteria for the assessment of both types of characteristic, are desperately needed.

\section{"Abnormal posture, repetitive tasks, lack of support from colleagues, high demands, and poor control over work may lead to neck pain"}

Taken together therefore, the evidence suggests that neck pain and neck disorders are associated with mechanical and psychosocial workplace factors. To date, the preventive effectiveness of neck schools, based predominantly upon ergonomic principles, is not convincing. ${ }^{17}$ Therefore, high on the research agenda for the future must be an evaluation programme for workplace prevention strategies aimed at reducing both mechanical and psychosocial risk factors.

\section{Association of shoulder disorders with occupation}

Shoulder pain is common, with a lifetime prevalence of $7-$ $10 \%$ and point prevalence of up to $26 \% .^{12}$ In a number of studies during the past decade, shoulder pain was second only to back pain in workers' compensation insurance claims. The associations of shoulder disorders and occupational factors have been widely studied, but the quality and methodology applied is once again variable. Notwithstanding, it was the conclusion of two systematic reviews that overhead work was an established risk factor, and that repetitive work was probably a risk factor. ${ }^{2}{ }^{10}$ There is evidence that cumulative intensive shoulder work, particularly incorporating combinations of exposures (for example, working overhead with a heavy tool), is associated with significantly increasing rates of prevalence of shoulder disorders. ${ }^{18}$

As with neck pain, however, the available evidence suggests that psychological and occupational psychosocial variables (for example, monotonous work) also have an important role. ${ }^{10}$ Harkness and colleagues recently studied factors that predict new onset shoulder pain among newly employed workers in 12 diverse occupational settings. ${ }^{19}$ The risk of incident shoulder pain was increased among workers exposed to lifting (odds ratio $(\mathrm{OR})=1.7,95 \%$ confidence interval (CI) 0.9 to 3.0), lifting at or above shoulder level $(\mathrm{OR}=1.6,95 \%$ CI 1.0 to 2.5$)$ and pushing or pulling $(\mathrm{OR}=1.9,95 \%$ CI 1.1 to 3.3). However, exposure to monotonous work was also predictive $(\mathrm{OR}=1.7,95 \%$ CI 0.9 to 1.9). Similarly, Andersen et al reported that new onset neck/shoulder pain among industrial and service workers was predicted by repetitive work with the shoulder, high job demands, and psychological distress. ${ }^{20}$ The association with psychosocial risk factors also holds true even when the outcome studied is a specific shoulder disorder: a current diagnosis of adhesive capsulitis has been found recently to be independently associated with exposure to overhead work $(\mathrm{OR}=2.8,95 \%$ CI 1.4 to 5.5$)$, work involving lifting weights 
$(\mathrm{OR}=1.8,95 \% \mathrm{CI} 1.1$ to 2.9$)$, poor workplace support from colleagues/supervisors ( $\mathrm{OR}=2.3,95 \% \mathrm{CI} 1.1$ to 4.6$)$, and psychological morbidity ( $\mathrm{OR}=4.3,95 \% \mathrm{CI} 1.2$ to 3.0$).{ }^{21}$

\section{Association of occupation with epicondylitis}

In 1948, Lambrecht reported an increase in the number of cases of lateral epicondylitis in the Federal Republic of Germany after the second world war. ${ }^{22} \mathrm{He}$ observed that those affected were frequently employed in unaccustomed strenuous work and that the dominant arm was much more commonly affected than the non-dominant one. Since this observation, many studies in different occupations have suggested an increased risk with exposure to strenuous manual occupations. In the meat processing industry, for example, several studies, including one that was prospective, have shown that female sausage makers and packaging/ folding workers and male meat cutters (all of whom were deemed to have exposure to strenuous manual tasks, as observed on factory visits) had an increased incidence of epicondylitis in comparison with their colleagues who were office workers or supervisors, with risk estimates ranging from 1.2-fold to 10.3-fold. ${ }^{23}$ Importantly, however, many of these jobs involve exposure to combinations of force, repetition, and/or vibration. It is not currently clear whether exposure to one of these factors in isolation can be provocative and neither is it clear whether mechanical factors initiate the disorder or aggravate a tendency among predisposed people. Until recently, the effect of psychological factors on epicondylitis had not been reported. However, a recent cross sectional community survey found that epicondylitis was statistically significantly associated with low levels of psychological wellbeing ( $\mathrm{OR}=7.9,95 \%$ CI 2.5 to 24.5) and that these effects were independent of associations with mechanical factors such as bending and straightening the elbow repetitively. ${ }^{24}$ To date, there are no prospective studies that elucidate the role of psychosocial factors in the aetiology of epicondylitis.

\section{Non-specific forearm pain ("repetitive strain injury")} In the 1980s, an epidemic of "repetitive strain injury" (RSI) swept Australia, in which predominantly female employees with occupations involving the use of keyboards presented with incapacitating arm pain that defied classification by any existing system. Preventive ergonomic measures (setting of maximum keystrokes, posture, ergonomic workstations, job rotation, rest breaks) were advocated. However, controversy beset this new diagnostic label: alternative views of RSI were that it was an epidemic hysteria or occupational neurosis. The medical and lay press condemned the epidemic as a massive fraud perpetrated by Australian workers using arm pain as a way of securing large compensation payments from their employers, but proponents of the biomechanical aetiology published findings on muscle fatigability, histomorphometry, blood flow, and peripheral sensorineural functioning that perpetuated the controversy. Whatever the truth about the Australian epidemic, the label RSI was at best tautological and at worst, probably harmful. ${ }^{7}$ The term should not be used in clinical practice and has been abandoned in epidemiological research. Since the publication of consensus workshops in the UK and Europe, ${ }^{5}{ }^{6}$ non-specific forearm pain has been adopted as the diagnostic label for patients presenting with forearm pain without diagnostic physical signs.

In their prospective study of the risk factors for nonspecific forearm pain, Macfarlane and colleagues found that new onset forearm pain was independently predicted by psychological distress ( $\mathrm{OR}=1.8,95 \%$ CI 0.8 to 4.1$)$, aspects of illness behaviour (OR $=6.6,95 \%$ CI 1.5 to 29), and other somatic symptoms, as well as psychosocial factors, such as level of satisfaction with support from supervisors/colleagues $(\mathrm{OR}=2.6,95 \% \mathrm{CI} 1.1$ to 5.8$)$, and mechanical factors (for example, repetitive tasks; OR $=2.9,95 \%$ CI 1.2 to 7.3$).{ }^{25}$ The authors recently reported that non-specific forearm pain as diagnosed by a validated examination algorithm was rare among working age adults (point prevalence $0.5 \%$ ) and that it was significantly associated with psychological distress $(\mathrm{OR}=5.3,95 \%$ CI 1.6 to 18.3$)$ but not with any mechanical exposures, including keyboard use or repetitive tasks. ${ }^{26}$

\section{Carpal tunnel syndrome and occupation}

The relationship between carpal tunnel syndrome (CTS) and physical workplace factors has been the subject of more than 30 epidemiological studies, the findings of which have been extensively reviewed ${ }^{2027-29} ; 17$ of these studies met criteria for inclusion into a recent meta-analysis. ${ }^{30}$ However, the putative role of workplace factors in the aetiology of CTS is one of the most hotly debated in current epidemiological publications. The principal source of controversy has been the problem of case definition; "what is carpal tunnel syndrome?" has been the subject of recent publications. ${ }^{31-35}$ Many of the available epidemiological studies, especially those undertaken in America, have used a case definition of symptoms and signs, in the absence of neurophysiological testing. As a result, studies of American populations have yielded consistently higher risk estimates than those derived from studies in Scandinavia, principally because more of the Scandinavian studies used neurophysiology. Overall, systematic reviews conclude that workplace factors are probably aetiologically contributory to CTS; exposure to force and/or repetitive motion are probably the most important factors, exposure to hand/wrist vibration and awkward forearm, wrist, and finger postures may also have a role.

\section{"The term 'non-specific forearm pain' should replace the tautological label 'repetitive strain injury"'}

It is to be hoped that the use of a more uniform approach to the diagnosis of CTS will clarify the role of physical workplace factors in this painful and debilitating condition. One recent Scandinavian study, using a consensus based case definition, found that CTS was more common in the dominant hand of people exposed to repetitive tasks ( $\mathrm{OR}=1.8,95 \% \mathrm{CI} 1.1$ to 3.2 ) and that exposure to repetitive and forceful work resulted in a 1.4-fold increased risk of CTS. ${ }^{34}$ The relationship of CTS with psychological morbidity has been largely unstudied, but a British study recently showed that $14 \%$ of adults presenting to outpatient departments with CTS had evidence of a major depressive disorder and that, in total, $22 \%$ had evidence of psychological comorbidity (rates comparable with those observed among outpatient adults with non-specific forearm pain in the same study). ${ }^{36}$

\section{DISCUSSION}

Since first mooted almost 300 years ago, there have been many epidemiological studies of the association between occupational factors and musculoskeletal problems. In general, this is a field beset with methodological difficulties. Differences of study design, classification criteria, outcome assessment, and interpretation have led to considerable confusion and controversy. Despite this, important developments have occurred in recent years. Starting with the NIOSH review in 1997, which synthesised these heterogeneous publications and drew up recommendations for research, many more studies have been designed and carried out. ${ }^{4-9} 11-15$ 18-21 24-6 29-37 One of the priority areas, that of classification criteria for the diagnosis of ULDs, has been examined by two European groups, ${ }^{56}$ who have developed consensus diagnostic criteria as a starting point for new epidemiological studies. Working from these, a new system 
of examination has been developed, which has been shown to be reliable between observers and to have face validity. ${ }^{8} 9$ These initiatives provide new tools suitable for use in epidemiological studies, which can produce reliable and valid assessment of outcomes.

Another notable development in this field is the recognition that occupation may contribute to upper limb conditions through psychosocial, as well as mechanical, mechanisms. In 1996, the NIOSH document synthesised the entire psychosocial literature into 16 pages out of the total 590 page document! Indeed, much of the early epidemiological literature focused only on mechanical workplace factors, thereby omitting a potentially modifiable aspect of workplace design. Since then, many more studies have focused on both mechanical and psychosocial factors, ${ }^{11} 121519-2124-631356$ and such studies have contributed additional insight into the relative importance of different workplace factors in the causation of ULDs. However, one of the other NIOSH recommendations, that valid and reliable measures of mechanical occupational exposures are needed, ${ }^{10}$ remains a key objective not only for mechanical exposures but also for psychosocial exposures. ${ }^{11}$

\section{"Diagnostic criteria for ULDs have been agreed and a new} system of examination developed"

An important research agenda still remains: understanding how best to develop programmes for the prevention of ULDs in the workplace. The results of recent studies suggest that interventions aimed at altering workers' perceptions of monotonous or tedious work, perhaps through better job development opportunities, increasing latitude over working patterns, or improved communication between employers and employees, as well as ergonomic interventions, might be cost effective and beneficial. However, longitudinal prevention studies which deal with both mechanical and psychosocial factors are still urgently required. ${ }^{37}$

\section{CONCLUSION}

Neck and upper limb pain is a common problem among working age adults and contributes importantly to sick leave. An association between workplace factors and such symptoms has long been mooted and evidence continues to accumulate that factors such as prolonged abnormal posture and repetition contribute markedly to such conditions. More recent studies that have considered psychosocial influences have suggested that the aetiology of these conditions is complex and that both types of factor may well be important. To date, however, the methodological weaknesses discussed in the first part of this review make it impossible for conclusions to be drawn about the relative importance of mechanical and psychosocial risk factors in the aetiology of ULDs. Although progress is slow, the quality of epidemiological studies has improved and new developments in classification and study design will contribute considerably to the evidence base in this field over the next decade. Primary and secondary prevention trials, however, still remain elusive.

\section{ACKNOWLEDGEMENTS}

We acknowledge the support of the Arthritis Research Campaign, the Colt Foundation, and the Health \& Safety Executive, UK. The Medical Research council provided infrastructure support. Dr Walker-Bone was supported by an Arthritis Research Campaign Clinical Research Fellowship 1999-2002.

\section{Authors' affiliations}

K Walker-Bone, Brighton and Sussex Medical School, Mayfield House, University of Brighton, Falmer, Brighton BN1 9PH, UK

C Cooper, MRC Epidemiology Centre, Southampton General Hospital, Tremona Road, Southampton SO16 6YD, UK
Acting editor: Anthony D Woolf

\section{REFERENCES}

1 Ramazzini B. De morbis artificum [first published 1713]. Chicago, University of Chicago, 1940.

2 Kuorinka I, Forcier, eds. Work related musculoskeletal disorders (WMSD): a reference book for prevention, London, Taylor \& Francis, 1995:17-137.

3 Helliwell P. Diagnostic criteria for work-related upper limb disorders. Br J Rheumatol 1996;35:1195-6.

4 Van Eerd D, Beaton D, Cole D, Lucas J, Hogg-Johnson S, Bombardier C. Classification systems for upper-limb musculoskeletal disorders among workers: a review of the literature. J Clin Epidemiol 2003;56:940-2.

5 Harrington JM, Carter JT, Birrell L, Gompertz D. Surveillance case definitions for work related upper limb pain syndromes. Occup Environ Med 1998;55:264-71.

6 Sluiter J, Rest KM, Frings-Dresen MHW. Criteria document for evaluating the work-relatedness of upper extremity musculoskeletal disorders. Scand J Work Environ Health $2001 ; 27$ (suppl 1): 1-102.

7 Helliwell PS, Bennett RM, Littlejohn G, Muirden KD, Wigley RD. Towards epidemiological criteria for soft-tissue disorders of the arm. Occup Med 2003:53:313-19.

8 Walker-Bone K, Byng P, Linaker C, Reading I, Coggon D, Palmer KT, et al. Reliability of the Southampton examination schedule for the diagnosis of upper limb disorders in the general population. Ann Rheum Dis 2002;61:103-6.

9 Palmer KT, Walker-Bone K, Linaker C, Reading I, Kellingray S, Coggon D, et al. The Southampton examination schedule for the diagnosis of musculoskeletal disorders of the neck and upper limb. Ann Rheum Dis 2000;59:5-11

10 Bernard BP, ed. Musculoskeletal disorders (MSDs) and workplace factors. Cincinnati (OH): US Department of Health and Human Services, 1997.

11 Bongers P, Kremer AM, ter Laak J. Are psychosocial factors risk factors for symptoms and signs of the shoulder, elbow or hand/wrist? A review of the epidemiological literature. Am J Ind Med 2002;41:315-42.

12 Walker-Bone K, Palmer KT, Reading I, Cooper C. Soft tissue rheumatic disorders of the neck and upper limb: prevalence and risk factors. Semin Arthritis Rheum 2003;33:185-203.

13 Buchbinder R, Goel V, Bombardier C, Hogg-Johnson S. Classification systems of soft tissue musculoskeletal disorders of the neck and upper limb: do they satisfy methodological guidelines? J Clin Epidemiol 1996;49:141-9.

14 Ariens GAM, van Mechelen W, Bongers P, Bouter LM, van der Wal G, Physical risk factors for neck pain. Scand J Work Environ Health 2000;26:7-19.

15 Croft PR, Lewis M, Papageorgiou AC, Thomas E, Jayson MIV, Macfarlane GJ, et al. Risk factors for neck pain: a longitudinal study in the general population. Pain 2001;93:317-25.

16 Leino P, Magni G. Depressive and distress symptoms as predictors of low back pain, neck-shoulder pain, and other musculoskeletal morbidity: a 10-year follow-up of metal industry employees. Pain 1993;53:89-94.

17 Kamwendo K, Linton SJ. A controlled study of the effect of neck school in medical secretaries. J Rehabil Med 1991;23:143-52.

18 Frost $\mathbf{P}$, Andersen JH. Shoulder impingement syndrome in relation to shoulder intensive work. Occup Environ Med 1999:56:494-8.

19 Harkness EF, Macfarlane GJ, Nahit ES, Silman AJ, McBeth J. Mechanical and psychosocial factors predict new onset shoulder pain: a prospective cohort study of newly employed workers. Occup Environ Med 2003;60:850-7.

20 Andersen JH, Kaergaard A, Mikkelsen S, Jensen UF, Frost P, Bonde JP, et al. Risk factors in the onset of neck/shoulder pain in a prospective study of workers in industrial and service companies. Occup Environ Med 2003;60:649-54

21 Walker-Bone K, Reading I, Palmer K, Coggon D, Cooper C. The epidemiology of adhesive capsulitis among working-aged adults in the general population [abstract]. Rheumatology (Oxford) 2004;43(suppl 1):S143.

22 Lambrecht W. Wesen und behandlung der epicondylitis humeri. Chirurgie 1948;19:55-8.

23 Viikari-Juntura E, Kurppa K, Kuosma E, Huuskonen M, Kivi P. Prevalence of epicondylitis and tenosyovitis among meatcutters. Scand J Work Environ Health 1991; 17:32-7.

24 Walker-Bone K, Palmer K, Reading I, Coggon D, Cooper C. Lateral epicondylitis among the general population: a case-control study [abstract]. Rheumatology (Oxford) 2004;43(suppl 1):S196.

25 Macfarlane GJ, Hunt IM, Silman AJ. Role of mechanical and psychosocial factors in the onset of forearm pain: prospective population based study. BMJ 2000;321:1-5.

26 Walker-Bone K, Reading I, Palmer KT, Coggon D, Cooper C. 'Repetitive strain injury' is rare among working-aged adults and is not associated with keyboard use [abstract]. Rheumatology (Oxford), 2004;43(suppl 1):S199.

27 Stock S. Workplace ergonomic factors and the development of musculoskeletal disorders of the neck and upper limb. Am J Ind Med 1991; 19:87-107.

28 Moore JS. Carpal tunnel syndrome. Occup Med: State of the Art Rev 1992;7:741-63.

29 Gerr $F$, Letz R. The sensitivity and specificity of tests for carpal tunnel syndrome vary with the comparison groups. J Hand Surg Br 1998;23:151-5.

30 Abbas MEF, Abdelmonem AA, Zhang ZW, Kraus JF. Meta-analysis of published studies of work-related carpal tunnel syndrome. Int J Occup Environ Health 1998;4:160-7. 
31 Walker-Bone K, Reading I, Palmer K, Cooper C. Criteria for assessing pain and nonarticular soft-tissue rheumatic disorders of the neck and upper limb. Semin Arthritis Rheum 2003;33:168-84.

32 D'Arcy CA, McGee S. Does this patient have carpal tunnel syndrome? JAMA 2000;283:3110-17.

33 Franzblau A, Werner RA. What is carpal tunnel syndrome? JAMA 1999;282:186-7.

34 Thomsen JF. Repetitive work and carpal tunnel syndrome. Denmark: University of Copenhagen [PhD thesis.]
35 Reading I, Walker-Bone K, Palmer KT, Cooper C, Coggon D. Anatomica distribution of sensory symptoms in the hand and their relation to neck pain, psychosocial variables and occupational activities. Am J Epidemiol 2003;157:524-30.

36 White PD, Henderson M, Pearson RM, Coldrick AR, White AG, Kidd BL. Illness behaviour and psychosocial factors in diffuse upper-limb pain disorder: a case-control study. J Rheumatol 2003;30:139-45.

37 Silverstein B, Clark R. Interventions to reduce work-related musculoskeletal disorders. J Electromyogr Kinesiol 2004;14:135-52.

\section{$\mathrm{ECHO}$}

\section{Physical activity brings mass benefit in arthritis}

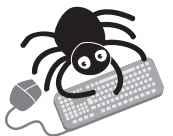

Please visit the Annals of the Rheumatic Diseases website [www. annrheumdis. com] for a link to the full text of this article. ncreasing physical activity may promote physical and mental wellbeing in people with arthritis and bring huge public health benefits, authors of a North American survey have suggested-the first so far to investigate physical activity, health related quality of life (HRQOL), and arthritis together on a population scale. It should help to reduce the burden of ill health they found with inactivity, and they recommend that exercise programmes are developed for all functional levels.

Self reported data from 212000 respondents from all 50 states and the district of Columbia showed conclusively that people with arthritis who were inactive by federal state criteria were significantly more likely to have more physical and mental ill health-14-30 days in the previous month-than those who complied. This was especially true for inactive women, with odds ratios of 2.39 for mental and 1.33 for physical health; inactive men had ratios of 2.19 and 1.56, respectively. Although cause and effect cannot be assumed in the cross sectional survey, this should prove to be the case, on past evidence.

The BRFSS (behavioural risk factor surveillance system) survey used was designed to capture uniform state specific data on preventive health practices and risk behaviours associated with chronic diseases in adults and collects data from a sample population-one per household.

Regular physical activity can reduce pain, increase function, and delay disability in arthritis. However, the relation between physical activity and HRQOL has not been well enough investigated before in the general population or in those with arthritis.

A Abell JE, et al. Journal of Epidemiology and Community Health 2005;59:380-385. 
by these factors than the hip joint. However the underlying reasons for these findings remain unclear.

Acknowledgements: We thank all the women who participated in the Million Women Study, collaborators from the NHS Breast Screening Centres, members of the study co-ordinating centre, and the study steering committee. We also thank the Information Centre for Health and Social Care and ISD Scotland for the linkage to the hospital records.

Funding: This research was funded by Cancer Research UK, the NHS Breast Screening Programme and the Medical Research Council. The study sponsors were not involved in the design, analysis, interpretation or writing of this report.

Competing interests: None.

Ethics approval: The study has been approved by the Eastern Multi-Centre Research Ethics Committee and all study participants provided written consent to be included.

\section{REFERENCES}

1. Srikanth VK, Fryer JL, Zhai G, Winzenberg TM, Hosmer D, Jones G. A meta-analysis of sex differences prevalence, incidence and severity of osteoarthritis. Osteoarthritis Cartilage 2005;13:769-81.

2. Felson $\mathbf{D}$, Zhang $Y$. An update on the epidemiology of knee and hip osteoarthritis with a view to prevention. Arthritis Rheum 1998;41:1343-55.

3. Silman A, Newman J. Obstetric and gynaecological factors in susceptibility to peripheral joint osteoarthritis. Ann Rheum Dis 1996;55:671-3.

4. Reginster J-Y, Kvasz A, Bruyere 0 , Henrotin Y. Is there any rationale for prescribing hormone replacement therapy (HRT) to prevent or treat osteoarthritis? Osteoarthritis Cartilage 2003;11:87-91.

5. Million Women Study Collaborators. The Million Women Study: design and characteristics of the study population. Breast Cancer Res 1999:1:73-80.

6. Million Women Study Collaborators. Breast cancer and hormone-replacement therapy in the Million Women Study. Lancet 2003;362:419-27.

7. Liu B, Balkwill A, Spencer E, Beral V. Relationship between body mass index and length of hospital stay for gallbladder disease. J Pub Health 2008;30:161-6.

8. NHS. Hospital Episode Statistics. http://www. hesonline.nhs.uk (accessed 2007).

9. Kendrick S, Clarke J. The Scottish record linkage system. Health Bull 1993;51:72-9.

10. World Health Organization. International statistical classification of diseases and related health problems, 10th revised edn. Geneva, Switzerland: World Health Organization, 1992.

11. Office of Population Censuses and Surveys. Classification of surgical operations and procedures, 4th revised edn. London, UK: Crown Copyright, 2000.

12. Karlson EW, Mandl LA, Aweh GN, Sangha O, Liang MH, Grodstein F. Risk factors for hip replacement due to osteoarthritis. Am J Med 2003:114:93-8.

13. Dennison E, Arden N, Kellingray S, Croft P, Coggan D, Cooper C. Hormone replacement therapy, other reproductive variables and symptomatic hip osteoarthritis in elderly white women: a case-control study. Br J Rheumatol 1998:37:1198-202.

14. Dawson J, Juszczak E, Thorogood M, Marks S-A, Dodd C, Fitzpatrick R. An investigation of risk factors for symptomatic osteoarthritis of the knee in women usng a life course approach. J Epidemiol Comm Health 2003;57:823-30.

15. Samanta A, Jones A, Regan M, Wilson S, Doherty M. Is osteoarthritis in women affected by hormonal changes or smoking? Br J Rheumatol 1993;32:366-70.

16. Spector TD, Roman E, Silman AJ. The pill, parity, and rheumatoid arthritis. Arthritis Rheum 1990;33:782-9.
17. Tepper $\mathbf{S}$, Hochberg M. Factors associated with hip osteoarthritis: data from the First National Health and Nutrition Examination (NHANES-1). Am J Epidemiol 1993;137:1081-8

18. Anderson J, Felson DT. Factors associated with osteoarthritis of the knee in the first National Health and Nutrition Examination Survey (HANES 1). Am J Epidemiol 1988:128:179-89

19. Cooley H, Stankovich J, Jones G. The association between hormonal and reproductive factors and hand osteoarthritis. Maturitas 2003;45:257-65

20. Sandmark H, Hogstedt C, Lewold S, Vingard E. Osteoarthrosis of the knee in men and women in association with overweight, smoking, and hormone therapy. Ann Rheum Dis 1999;58:151-5

21. Vinagard E, Alfredsson L, Malchau H. Lifestyle factors and hip arthrosis. Acta Orthop Scand 1997;68:216-20.

22. Parazzini F, Progetto Menopausa Italia Study Group. Menopausal status, hormone replacement therapy use and risk of self-reported physician-diagnosed osteoarthritis in women attending menopause clinics in Italy. Maturitas 2003;46:207-12.

23. Arden N, Nevitt M. Osteoarthritis: epidemiology. Best Pract Res Clin Rheumatol 2006:20:3-25.

24. Cirillo D, Wallace R, Wu L, Yood R. Effect of hormone therapy on risk of hip and knee joint replacement in the Women's Health Initiative. Arthritis Rheum 2006:54:3194-204.

25. Purdie D. Hormone replacement therapy and osteoporosis. In: Critchley H, Gebbie A Beral V, eds. Menopause and hormone replacement. London, UK: RCOG Press, 2004.

26. Hannan MT, Anderson JJ, Zhang Y, Levy D, Felson D. Bone mineral density and knee osteoarthritis in elderly men and women. Arthritis Rheum 1993;36:1671-80.

27. Hochberg MC, Lethbridge-Cejku M, Tobin J. Bone mineral density and osteoarthritis: Data from the Baltimore Longitudinal Study of Aging. Osteoarthritis Cartilage 2003:12:S45-8.

28. Wluka A, Davis S, Bailey M, Stuckey S, Cicuittini F. Users of oestrogen replacement therapy have more knee cartilage than non-users. Ann Rheum Dis 2000;60:332-6.

29. Felson DT, Nevitt MC. The effects of estrogen on osteoarthritis. Curr Opin Rheumatol 1998:10:269-72.

30. Liu B, Balkwill A, Banks E, Cooper C, Green J, Beral V. Relationship of height, weight and body mass index to the risk of hip and knee replacements in middle-aged women. Rheumatology 2007:46:861-7.

31. Liu B, Sweetland S, Beral V, Green J, Balkwill A, Casabonne D. Self-reported information on joint replacement and cholecystectomy agrees well with that in medical records. J Clin Epidemiol 2007;60:1190-4.

32. Dixon T, Shaw M, Ebrahim S, Dieppe P. Trends in hip and knee joint replacement: socioeconomic inequalities and projections of need. Ann Rheum Dis 2004:63:825-30.

33. Dixon T, Shaw ME, Dieppe PA. Analysis of regional variation in hip and knee join replacement rates in England using hospital episodes statistics. Public Health 2006:120:83-90

34. Banks E, Beral V, Cameron R, Hogg A, Langley N, Barnes I, et al. Agreement between general practice prescription data and self-reported use of hormone replacement therapy and treatment for various illnesses. J Epidemiol Biostat 2001;6:357-63

35. Cooper R, Blell M, Hardy R, Black S, Pollard TM, Wadsworth MEJ, et al. Validity of age at menarche self-reported in adulthood. J Epidemiol Comm Health 2006:60:993-7.

36. Dieppe P, Basler H-D, Chard J, Croft P, Dixon J, Hurley M, et al. Knee replacement surgery for osteoarthritis: effectiveness, practice variations, indications and possible determinants of utilization. Rheumatology 1999;38:73-83.

37. Woolf A, Pfleger B. Burden of major musculoskeletal conditions. Bull World Health Organ 2003;81:646-56.

\section{RETRACTION}

The journal would like to retract the following paper-Hard work never hurt anyone: or did it? A review of occupational associations with soft tissue musculoskeletal disorders of the neck and upper limb (K Walker-Bone and C Cooper. Ann Rheum Dis 2005;64:1391-6)—as it was published earlier that year on pp 1112-17. 